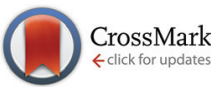

Cite this: Org. Biomol. Chem., 2015, 13, 5617

Received 26th February 2015, Accepted 13th April 2015

DOI: 10.1039/c5ob00389j

www.rsc.org/obc

\section{A preorganized $\beta$-amino acid bearing a guanidinium side chain and its use in cell-penetrating peptides $\uparrow$}

\author{
Yosuke Demizu, ${ }^{\star a, b}$ Makoto Oba, ${ }^{c}$ Koyo Okitsu, ${ }^{\text {b,d }}$ Hiroko Yamashita, ${ }^{\text {b,d }}$ \\ Takashi Misawa, ${ }^{b}$ Masakazu Tanaka, ${ }^{c}$ Masaaki Kuriharab,d and Samuel H. Gellman ${ }^{a}$
}

\begin{abstract}
A cyclic $\beta$-amino acid (APC ${ }^{\mathrm{Gu}}$ ) bearing a side-chain guanidinium group has been developed. The APC $^{\mathrm{Gu}}$ residue was incorporated into an $\alpha / \beta$-peptide based on the Tat(47-57) fragment, leading to an oligomer with substantial helicity in methanol that enters HeLa cells much more readily than does the corresponding Tat $\alpha$-peptide.
\end{abstract}

Cell-penetrating peptides (CPPs) can deliver various molecules, including drugs, proteins, and DNA, into cells. ${ }^{1-5}$ To date, a variety of CPPs has been developed, many of which are rich in arginine, including oligo-arginines $(\mathrm{Arg})_{n}$ and the HIV Tat(47-57) peptide. ${ }^{6-11}$ The guanidino moiety of Arg appears to play a crucial role in the cell entry process, ${ }^{6-9}$ and the internalization of these CPPs occurs via endocytosis as one of the major routes of the endocytic uptake. However, in the presence of counterions such as pyrenebutyrate, the CPPs such as $(\operatorname{Arg})_{8}$ were internalized by direct translocation through plasma membranes. ${ }^{12}$ Indeed, many unnatural oligomers that possess multiple guanidino side chains, including peptoids, ${ }^{13} \alpha$-peptides, ${ }^{14} \beta$-peptides, ${ }^{15-18}$ and oligocarbamates ${ }^{19}$ can enter cells. Previously it was shown that the efficiency of cell entry by $\beta$-peptides can be enhanced by increasing helicity. ${ }^{20}$ This conformational stabilization was achieved by using cyclic $\beta$ residues. Here we extend this concept to oligomers with a heterogeneous backbone, containing both $\alpha$ - and $\beta$-amino acid residues (" $\alpha / \beta$-peptides").

$\alpha / \beta$-Peptides containing $25-33 \% \beta$ residues that are evenly distributed among the $\alpha$ residues have been shown to adopt a helical conformation that is very similar to the well-known $\alpha$-helix formed by pure $\alpha$-peptide backbones. ${ }^{21-24}$ This type of $\alpha / \beta$-peptide helix can be stabilized by the use of $\beta$ residues with a five-membered ring constraint and trans disposition of the amino and carboxyl groups. Two specific examples of this type of constrained $\beta$ residue have been widely explored, trans2-aminocyclopentane-1-carboxylic acid (ACPC) and trans-4aminopyrrolidine-3-carboxylic acid (APC). The pyrrolidine ring amino group of APC can be used to attach other peripheral units. ${ }^{25}$ Here we introduce a new derivative of APC in which the pyrrolidine nitrogen forms part of a guanidino group $\left(\mathrm{APC}^{\mathrm{Gu}}\right)$. We describe the preparation of a protected $\beta$-amino acid that can be used to incorporate $\mathrm{APC}^{\mathrm{Gu}}$ residues via solidphase synthesis. In addition, we evaluate the cell-penetrating ability of an $\mathrm{APC}^{\mathrm{Gu}}$-containing $\alpha / \beta$-peptide based on Tat$(47-57),{ }^{26,27}$ and show that the helicity provided by the new $\beta$ residue correlates with enhanced activity (Fig. 1).

The synthetic route to Fmoc- $(3 S, 4 R)-\mathrm{APC}^{\mathrm{Gu}}-\mathrm{OH}(3)$ is shown in Scheme 1. Fmoc- $(3 S, 4 R)-\mathrm{APC}^{\mathrm{Boc}}-\mathrm{OH}(\mathbf{1})$ was prepared by the reported method. ${ }^{28}$ The side-chain Boc group was removed under acidic conditions to give Fmoc- $(3 S, 4 R)-\mathrm{APC}-\mathrm{OH}(2)$ in quantitative yield. Guanidinylation of the side-chain amino group in 2 was accomplished by treatment with 3 equivalents of $N, N^{\prime}$-di-Boc- $N N^{\prime \prime}$-triflylguanidine under basic conditions. ${ }^{29}$

Building block 3 was used to prepare an $\alpha / \beta$-peptide analogue of Tat(47-57) containing $\mathrm{APC}^{\mathrm{Gu}}$ residues at positions 3, 7 and 10, to generate Tat-1. Two analogous $\alpha / \beta$-peptides were prepared as well, Tat-2, which has $\beta$-Arg at positions 3, 7 and 10, and Tat-3, which has APC at these three positions. Two versions of the $\alpha$-peptide Tat and the three $\alpha / \beta$-peptides were synthesized, one set bearing N-terminal fluorescein (6FAM) labels

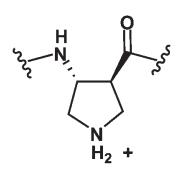

$(3 S, 4 R)$-APC

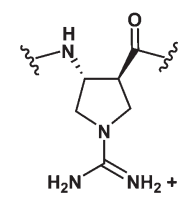

$(3 S, 4 R)-\mathrm{APC}^{\mathrm{Gu}}$
Fig. 1 Chemical structures of $(3 S, 4 R)-A P C$ and $(3 S, 4 R)-$ APC $^{\mathrm{Gu}}$. 


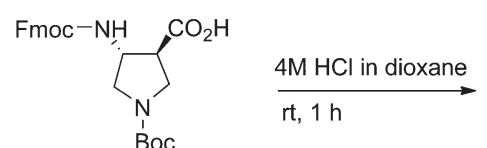

Fmoc-(3S,4R)-APC ${ }^{\text {Boc }-O H ~(1) ~}$

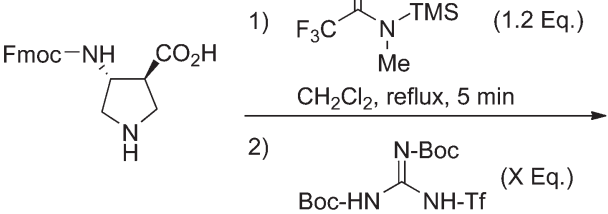

Fmoc-(3S,4R)-APC-OH (2) $>99 \%$

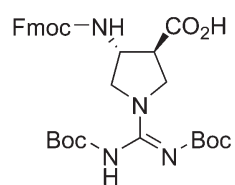

Fmoc-(3S,4R)-APC ${ }^{\mathrm{Gu}}-\mathrm{OH}(3)$

$\mathrm{X}=1.2: 63 \%$

$=2.0: 82 \%$

$=3.0: 95 \%$

Scheme 1 Synthesis of Fmoc-(3S,4R)-APC ${ }^{\mathrm{Gu}}-\mathrm{OH}(3)$.

(F-Tat, F-Tat-1, F-Tat-2 and F-Tat-3), and another set bearing acetyl groups at the N-termini (Ac-Tat, Ac-Tat-1, Ac-Tat-2 and Ac-Tat-3). Microwave-assisted solid-phase methods were used in each case, and each peptide was purified by reverse-phase HPLC and characterized by MALDI mass spectrometry (Fig. 2). ${ }^{30}$

We examined the abilities of F-Tat and the three analogous $\alpha / \beta$-peptides F-Tat-1-3 to enter HeLa cells. After incubation of cells with each compound for $2 \mathrm{~h}$ at $37^{\circ} \mathrm{C}$, the cells were lysed, and the fluorescence intensity of the lysate was measured. The $\alpha / \beta$-peptides entered cells more efficiently than the $\alpha$-peptide F-Tat. In particular, F-Tat-1, containing $(3 S, 4 R)-\mathrm{APC}^{\mathrm{Gu}}\left(\mathrm{Z}^{\mathrm{g}}\right)$ residues, showed a 65-fold higher extent of entry relative to F-Tat (Fig. 3).

Fig. 4 shows the effects of three endocytosis pathway inhibitors on entry of F-Tat and F-Tat-1-3 into HeLa cells. ${ }^{31-34}$ Amiloride is an inhibitor of macropinocytosis, ${ }^{33,34}$ chlorpromazine is an inhibitor of clathrin-mediated endocytosis, ${ }^{32}$ and filipin is an inhibitor of caveolae-mediated endocytosis. ${ }^{32-34}$ None of these agents hindered the uptake of $\alpha$-peptide F-Tat or F-Tat-2 ( $\beta$ residues $=\beta^{3}$-hArg) which suggests that cell entry by these two molecules involves pathways other than the three inhibitors. In contrast, amiloride inhibited cell entry by F-Tat-3 ( $\beta$ residues $=$ APC $)$, which suggests that macropinocytosis is at least partially responsible for entry in this case. The uptake level of F-Tat-1 $\left(\beta\right.$ residues $=$ APC $\left.^{\mathrm{Gu}}\right)$ was inhibited by both amiloride and chlorpromazine, which suggests that both macropinocytosis and clathrin-mediated endocytosis contribute to
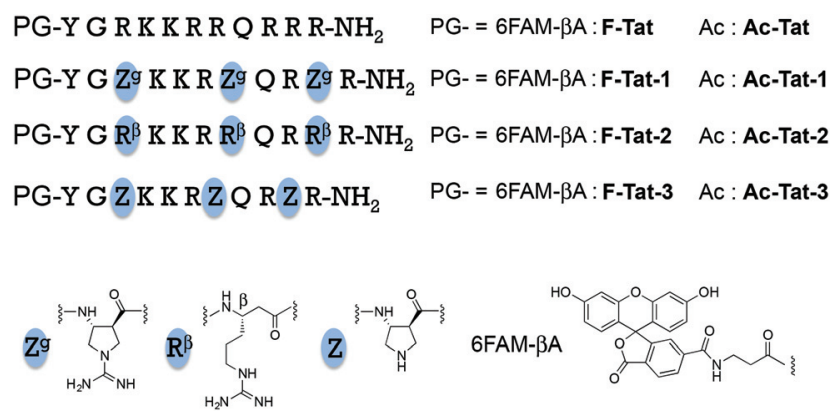

Fig. 2 Sequences of Tat derivatives Tat and Tat-1-3.

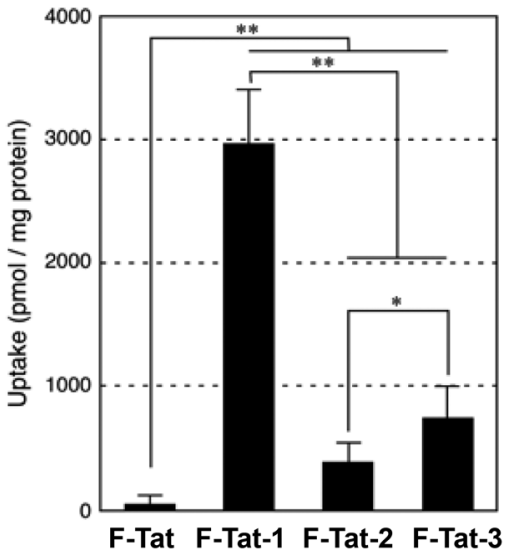

Fig. 3 Cellular uptake of F-Tat and F-Tat-1-3 at a concentration of $1 \mu \mathrm{M}$ (incubation time: $2 \mathrm{~h}$ ). Error bars represent standard deviation, $n=$ 5. ${ }^{*} p<0.05,{ }^{* *} p<0.01$.

A

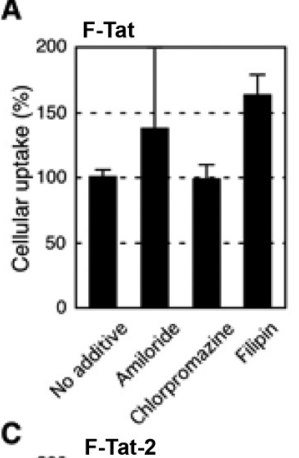

B
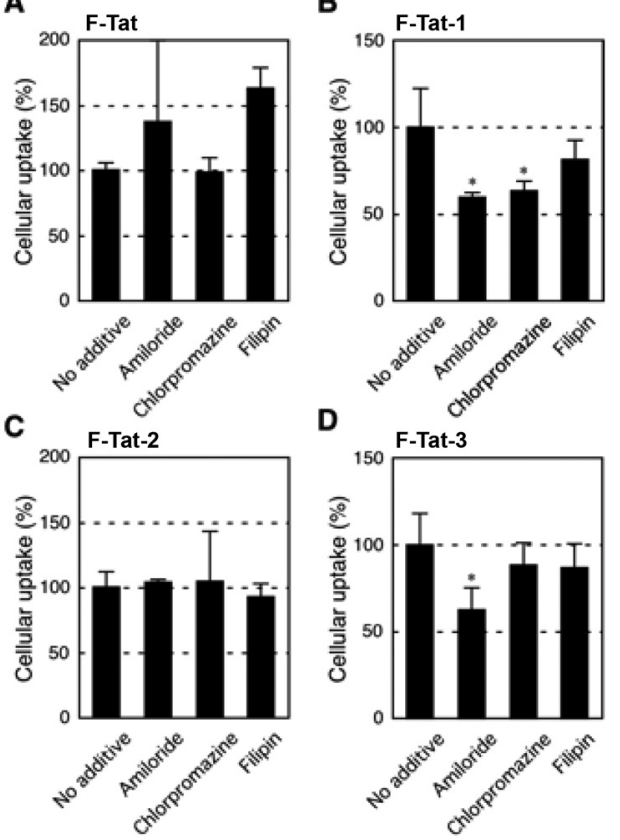

D

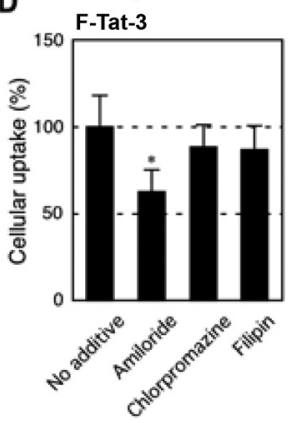

Fig. 4 Effects of inhibitors on internalization of F-Tat and F-Tat-1-3 at a concentration of $1 \mu \mathrm{M}$ (incubation time: $2 \mathrm{~h}$ ). Error bars represent standard deviation, $n=5 .{ }^{*} p<0.05,{ }^{* *} p<0.01$. 

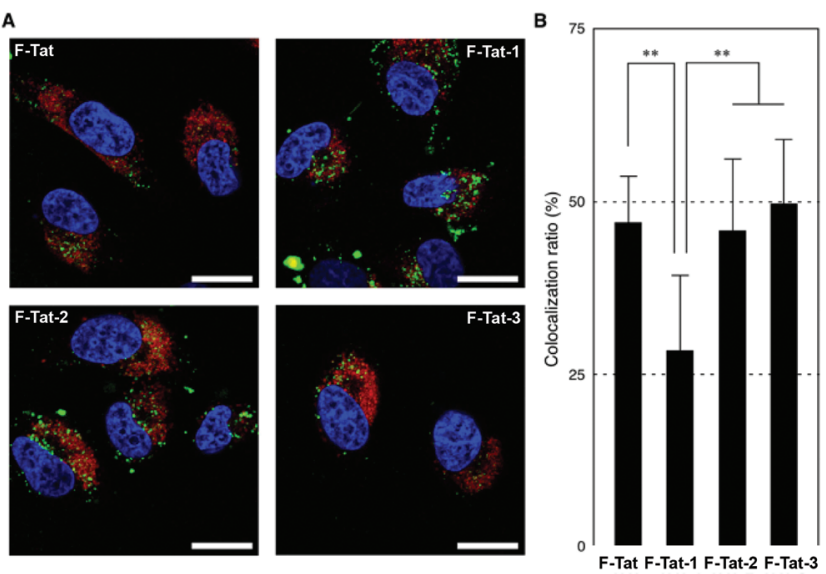

Fig. 5 Intracellular distribution of F-Tat and F-Tat-1-3 (green) at a concentration of $1 \mu \mathrm{M}$ (incubation time: $2 \mathrm{~h}$ ). The acidic late endosomes/ lysosomes were stained with LysoTracker Red (red) and the nuclei were stained with Hoechst 33342 (blue). (A) CLSM images of HeLa cells treated with Tat peptide derivatives. The scale bars represent $20 \mu \mathrm{m}$. (B) Quantification of Tat peptide derivatives colocalized with LysoTracker Red. Error bars in the graph represent standard deviation, $n=15$. ${ }^{* *} p<0.01$.

cell entry in this case. Low temperature $\left(4^{\circ} \mathrm{C}\right)$ incubation almost completely inhibited the internalization of $\mathbf{F}$-Tat and F-Tat-1-3 (Fig. S2 $\dagger$ ), suggesting that these peptides were mainly internalized into the cells via endocytosis.

The intracellular distribution of F-Tat and $\alpha / \beta$-peptides F-Tat-1-3 (green) in HeLa cells was assessed by confocal laser scanning microscopy (CLSM) after staining late endosomes/ lysosomes with LysoTracker Red (red) and nuclei with Hoechst 33342 (blue). All four peptides co-localized with the late endosomes/lysosomes, as shown in Fig. $5 .^{35,36}$ Roughly $50 \%$ of F-Tat, F-Tat-2 and F-Tat-3 were localized in the late endosomes/lysosomes, while $<30 \%$ of F-Tat-1 was localized in this way. This difference could arise if the distinctive entry mechanism of F-Tat-1, involving both macropinocytosis and clathrinmediated endocytosis, causes this molecule to be delivered to a different sub-cellular region relative to the other three. An alternative possibility is that F-Tat-1 is better able to move out of vesicles than the other three peptides, and therefore most of the F-Tat-1 fluorescence is diffusely distributed throughout the cytoplasm. ${ }^{37,38}$ Research to clarify the underlying mechanism of F-Tat-1 is now under way in our group, and the results will be reported elsewhere in the near future.

The conformations of Ac-Tat and Ac-Tat-1-3 were analyzed via circular dichroism (CD) in $\mathrm{MeOH}$ (Fig. 6). The $\alpha / \beta$-peptides containing cyclic $\beta$ residues (Ac-Tat-1 and Ac-Tat-3) showed a minimum at around $207 \mathrm{~nm}$, which is similar to the minima observed in CD spectra of $\alpha / \beta$-peptides that form right-handed $(P)$ helices (Fig. 6). ${ }^{39,40}$ Furthermore, addition of $10 \mathrm{mM}$ SDS has little effect on the helical structures of Tat-1 and Tat-3 (Fig. S3†). On the other hand, Ac-Tat and Ac-Tat-2, which contain exclusively acyclic residues, show weaker CD signatures that suggest little or no folding.

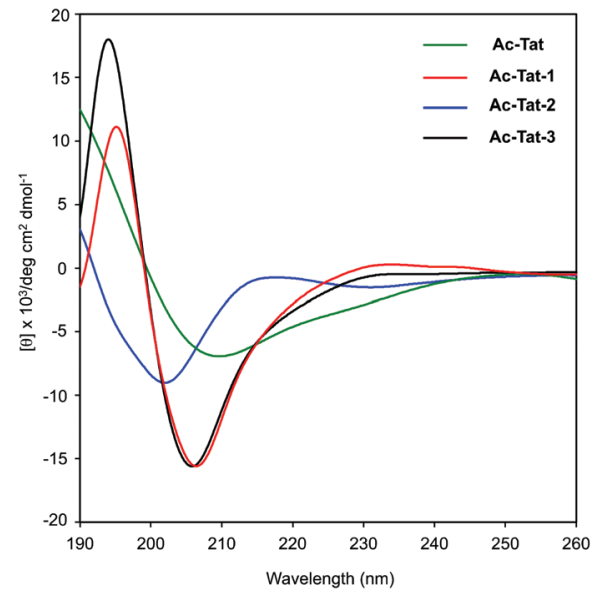

Fig. 6 CD spectra in the 190-260 nm region of Ac-Tat (green), Ac-Tat1 (red), Ac-Tat-2 (blue), and Ac-Tat-3 (black). Peptide concentration: $30 \mu \mathrm{M}$ in $\mathrm{MeOH}$ solution.

\section{Conclusions}

Tat-1 with $(3 S, 4 R)-\mathrm{APC}^{\mathrm{Gu}}\left(\mathrm{Z}^{\mathrm{g}}\right)$, Tat-2 with $\beta^{3}$-Arg $\left(\mathrm{R}^{\beta}\right)$, and Tat-3 with $(3 S, 4 R)$-APC $(\mathrm{Z})$ showed higher cell penetrating activities than the $\alpha$-peptide Tat in HeLa cells. In particular, Tat-1 showed a 65-fold higher permeability than Tat. These results indicate that stabilization of a helical secondary structure is synergistic with the presence of guanidino groups in promoting cell entry. It is noteworthy that Tat-3 which contains $(3 S, 4 R)$-APC residues and only three guanidino groups (on the three Arg residues) enters cells relatively efficiently. The new cyclic $\beta$-amino acid residue $\mathrm{APC}^{\mathrm{Gu}}$, which combines the advantages of conformational preorganization and a side-chain guanidino group should prove to be a useful tool for further development of biologically active $\beta$-peptides and $\alpha / \beta$-peptides.

\section{Acknowledgements}

This study was supported, in part, by JSPS postdoctoral fellowships for research abroad (Y.D.), and by JSPS KAKENHI grant number 26460169 (Y.D.). Work at UW-Madison was supported in part by NSF grant CHE-1307365.

\section{Notes and references}

1 I. Nakase, H. Akita, K. Kogure, A. Gráslund, Ü. Langel, H. Harashima and S. Futaki, Acc. Chem. Res., 2012, 45, 1132-1139.

2 J. M. Hyman, E. I. Geihe, B. M. Trantow, B. Parvin and P. A. Wender, Proc. Natl. Acad. Sci. U. S. A., 2012, 109, 13225-13230.

3 G. K. Seward, Q. Wei and I. J. Dmochowski, Bioconjugate Chem., 2008, 19, 2129-2135. 
4 B. Gupta, T. S. Levchenko and V. P. Torchilin, Adv. Drug Delivery Rev., 2005, 57, 637-651.

5 T. Nagakubo, Y. Demizu, Y. Kanda, T. Misawa, T. Shoda, K. Okuhira, Y. Sekino, M. Naito and M. Kurihara, Bioconjugate Chem., 2014, 25, 1921-1924.

6 C. M. Yamazaki, I. Nakase, H. Endo, S. Kishimoto, Y. Mashiyama, R. Masuda, S. Futaki and T. Koide, Angew. Chem., Int. Ed., 2013, 52, 5497-5500.

7 S. B. Fonseca, M. P. Pereira and S. O. Kelley, Adv. Drug Delivery Rev., 2009, 61, 953-964.

8 P. A. Wender, C. Wesley, E. A. Galliher, L. R. Jones and T. H. Pillow, Adv. Drug Delivery Rev., 2008, 60, 452-472.

9 S. Futaki, Biopolymers, 2006, 84, 241-249.

10 E. Dupont, A. Prochiantz and A. Joliot, Penetratin Story: an Overview, Methods Mol. Biol., 2011, 683, 21-29.

11 X. Wang, I. Huq and T. M. Rana, J. Am. Chem. Soc., 1997, 119, 6444-6445.

12 T. Takeuchi, M. Kosuge, A. Tadokoro, Y. Sugiura, M. Nishi, M. Kawata, N. Sakai, S. Matille and S. Futaki, ACS Chem. Biol., 2006, 1, 299-303.

13 P. A. Wender, D. J. Mitchell, K. Pattabiraman, E. T. Pelkey, L. Steinman and J. B. Rothbard, Proc. Natl. Acad. Sci. U. S. A., 2000, 97, 13003-13008.

14 J. Kuriakose, V. Hernandez, M. Nepal, A. Brezden, V. Pozzi, M. Seleem and J. Chmielewski, Angew. Chem., Int. Ed., 2013, 52, 9664-9667.

15 C. M. Goodman, S. Choi, S. Shandler and W. F. DeGrado, Nat. Chem. Biol., 2007, 3, 252-262.

16 D. Seebach, A. K. Beck and D. J. Bierbaum, Chem. Biodiversity, 2004, 1, 1111-1239.

17 R. P. Cheng, S. H. Gellman and W. F. DeGrado, Chem. Rev., 2001, 101, 3219-3232.

18 S. H. Gellman, Acc. Chem. Res., 1998, 31, 173-180.

19 P. A. Wender, J. B. Rothbard, T. C. Jessop, E. L. Kreider and B. L. Wylie, J. Am. Chem. Soc., 2002, 124, 13382-13383.

20 T. B. Potocky, A. K. Menon and S. H. Gellman, J. Am. Chem. Soc., 2005, 127, 3686-3687.

21 L. M. Johnson and S. H. Gellman, Methods Enzymol., 2013, 523, 407-429.

22 H. S. Haase, K. J. Peterson-Kaufman, S. K. Lan Levengood, J. W. Checco, W. L. Murphy and S. H. Gellman, J. Am. Chem. Soc., 2012, 134, 7652-7655.
23 M. D. Boersma, H. S. Haase, K. J. Peterson-Kaufman, E. F. Lee, O. B. Clarke, P. M. Colman, B. J. Smith, W. S. Horne, W. D. Fairlie and S. H. Gellman, J. Am. Chem. Soc., 2012, 134, 315-323.

24 J. L. Price, W. S. Horne and S. H. Gellman, J. Am. Chem. Soc., 2010, 132, 12378-12387.

25 H.-S. Lee, F. A. Syud, X. Wang and S. H. Gellman, J. Am. Chem. Soc., 2001, 123, 7721-7722.

26 T. B. Potocky, A. K. Menon and S. H. Gellman, J. Biol. Chem., 2003, 278, 50188-50194.

27 N. Umezawa, M. A. Gelman, M. C. Haigis, R. T. Raines and S. H. Gellman, J. Am. Chem. Soc., 2002, 124, 368369.

28 H.-S. Lee, P. R. LePlae, E. A. Porter and S. H. Gellman, J. Org. Chem., 2001, 66, 3597-3599.

29 K. Feichtinger, C. Zaph, H. L. Sings and M. Goodman, J. Org. Chem., 1998, 63, 3804-3805.

30 See the ESI. $\dagger$

31 J. Rejaman and A. Bragonzi, Mol. Ther., 2005, 12, 468474.

32 S. K. Lai, K. Hida, S. T. Man, C. Chen, C. Machamer, T. A. Schroer and J. Hanes, Biomaterials, 2007, 28, 28762884.

33 D. Mudhakir, H. Akita, E. Tan and H. Harashima, J. Controlled Release, 2008, 125, 164-173.

34 M. Oba and M. Tanaka, Biol. Pharm. Bull., 2012, 35, 10641068.

35 M. Oba, K. Aoyagi, K. Miyata, Y. Matsumoto, K. Itaka, N. Nishiyama, Y. Yamasaki, H. Koyama and K. Kataoka, Mol. Pharmaceutics, 2008, 5, 1080-1092.

36 S. Takae, K. Miyata, M. Oba, T. Ishii, N. Nishiyama, K. Itaka, Y. Yamasaki, H. Koyama and K. Kataoka, J. Am. Chem. Soc., 2008, 130, 6001-6009.

37 I. Nakase, T. Takeuchi, G. Tanaka and S. Futaki, Adv. Drug Delivery Rev., 2008, 60, 598-607.

38 M. M. Fretz, N. A. Penning, S. Al-Taei, S. Futaki, T. Takeuchi, I. Nakase, G. Storm and A. T. Jones, Biochem. J., 2007, 403, 335-342.

39 J. L. Price, W. S. Horne and S. H. Gellman, J. Am. Chem. Soc., 2007, 129, 6376-6377.

40 M. A. Schmitt, B. Weisblum and S. H. Gellman, J. Am. Chem. Soc., 2007, 129, 417-428. 